\title{
The effects of clay mineral property on hydrocarbon generation
}

\author{
JiNGONG CAI $^{1}$, JiAZONG DU ${ }^{1}$, TIANZHU LEI ${ }^{2}$, YINGLI LI ${ }^{1}$
}

${ }^{1}$ State Key Laboratory of Marine Geology, Tongji University, 200092 Shanghai, China

${ }^{2}$ Key laboratory of Petroleum Resources Research, Institute of Geology and Geophysics, Chinese Academy of Sciences, 730000 Lanzhou, China

Organic matter (OM) is intimately associated with clay minerals to form organo-clay complexes. The association plays crucial roles in affecting hydrocarbon generation of $\mathrm{OM}$. The variations hydrocarbons and mineralogy, especially their responding relationships and interactions worth deeply investigation. Therefore, smectite-octadecanoic acid complex (Sm-OA) and illite-octadecanoic acid complex (I-OA) were prepared for Closed system pyrolysis experiments. Then pyrolytic products were collected and measured. Meanwhile, mineralogy of residues was measured to investigate effects of different clay mineral properties on hydrocarbon generation mechanisms.

Results showed that hydrocarbon generation could be divided into three stages according to variations of hydrocarbon and mineralogy. A small peak of liquid products was located at $200-300^{\circ} \mathrm{C}$, followed by a high peak at 350 $450^{\circ} \mathrm{C}$, then gaseous hydrocarbons reached highest value at $500^{\circ} \mathrm{C}$. Correspondingly, mineralogical characteristics varied with temperature. In Sm-OA, smectite gradually converted into disordered I-Sm and then rapidly to ordered I-Sm. Bulk mineralogy was almost unchanged below $400^{\circ} \mathrm{C}$ and changed greatly above $400^{\circ} \mathrm{C}$. In I-OA, minor smectite totally converted into illite at first stage and crystal structure enhanced in later stages.

The comparison of pyrolytic products in Sm-OA and IOA indicated differentiation in hydrocarbon generation between organo-clay complexes formed by different clay minerals. Variations in mineralogy indicated minerals were reactant rather than catalyst in promoting hydrocarbon generation. Combining characteristics of mineralogy and hydrocarbon generation, it can be inferred that desorption of OM adsorbed by smectite and hydrogen denoted by Brønsted acid contributed to the high yield of liquid products below $400^{\circ} \mathrm{C}$. Above $400^{\circ} \mathrm{C}$, inorganic hydrogen denoted by acid and organic hydrogen supplied by condensation of $\mathrm{OM}$ promoted generation of saturated and gaseous hydrocarbons. Furthermore, the formation of ankerite indicated exitance of that decarboxylation of OM promoted by Lewis acid. These conclusions are significant for understanding hydrocarbon generation mechanisms and the potential of oil or gas exploration under different environments and buried depths. 